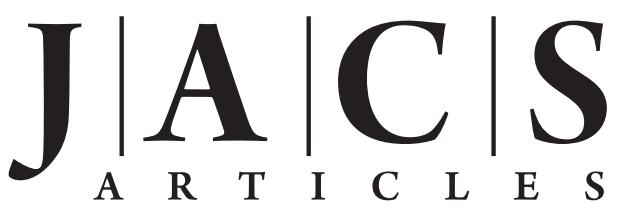

Published on Web 02/25/2009

\title{
Anion-Exchange Induced Phase Transformation of Mesostructured Silica
}

\author{
Ming-Chang Liu, ${ }^{\dagger}$ Hwo-Shuenn Sheu, ${ }^{\ddagger}$ and Soofin Cheng ${ }^{\star, \dagger}$ \\ Department of Chemistry, National Taiwan University, Taipei 106, Taiwan, and Research \\ Division, National Synchrotron Radiation Research Center, Hsinchu 300, Taiwan
}

Received October 11, 2008; E-mail: chem1031@ntu.edu.tw

\begin{abstract}
Mesostructured silica synthesized using cetyltriethylammonium (CTEA) ion as the pore-directing agent in acidic environments was ready to have interfacial anions exchanged at ambient temperature. In situ techniques including small-angle X-ray scattering (SAXS) and optical microscopy were used to examine the structural and morphological changes of the as-made mesostructured materials, and pyrene fluorescence quenching experiment was used to probe the variation in interfacial environment during the anion-exchange processes. About one-half of the interfacial anions between the silica framework and micelle were exchanged based on the fluorescence quenching experiments of pyrene, which was dissolved in the hydrophobic core of the micelle. Altering in the pore structure and the architecture of the silica framework was observed when the interfacial anions were exchanged by anions of higher salting-in power. The resultant phase transformation and morphological change were always toward pore structures of lower curvature. The influence of anion follows the Hofmeister series commonly encountered in macromolecular and biological systems. The mesophase transformation induced by the interfacial anion exchange provides a unique technique to study anions which are not yet included in the Hofmeister series.
\end{abstract}

\section{Introduction}

The surfactant-templated mesoporous materials of uniformly arranged pores with tunable pore diameter of $1.5-10 \mathrm{~nm}$ and very high surface areas (ca. $1000 \mathrm{~m}^{2} / \mathrm{g}$ ) are technologically promising for applications in catalysis, ${ }^{1-4}$ sensors, ${ }^{5,6}$ electronic devices, ${ }^{7}$ and biomedicines. ${ }^{8,9}$ An understanding of the forces governed the assembly processes, and interaction between the organic templates and the inorganic matrix in the formation of surfactant-templated mesoporous materials of uniformly arranged pores is of immense value not only in fabricating new porous materials but also in structural biology and medicine. The synthesis strategies involve the construction of extended organic architectures and self-assembly processes commonly encountered in biomineralization. ${ }^{10-14}$ The surfactant-templated synthesis of the mesoporous silica was mainly divided into two routes: the alkaline synthesis of M41S families and the acidic synthesis of SBA phases. ${ }^{10-15}$ The latter processes using acidic medium, low temperatures, and low concentrations of surfactants

†ational Taiwan University.

National Synchrotron Radiation Research Center.

(1) Das, D.; Lee, J. F.; Cheng, S. J. Catal. 2004, 223, 152.

(2) Thomas, J. M.; Raja, R. J. Organomet. Chem. 2004, 689, 4110.

(3) Shylesh, S.; Samuel, P. P.; Sisodiya, S.; Singh, A. P. Catal. Surv. Asia 2008, 12, 266.

(4) Hudson, S.; Cooney, J.; Magner, E. Angew. Chem., Int. Ed. 2008, 47, 8582.

(5) Melde, B. J.; Johnson, B. J.; Charles, P. T. Sensors 2008, 8, 5202.

(6) Ispas, C.; Sokolov, I.; Andreescu, S. Anal. Bioanal. Chem. 2008, 393 , 543.

(7) Yang, P. D.; Deng, T.; Zhao, D. Y.; Feng, P. Y.; Pine, D.; Chmelka, B. F.; Whitesides, G. M.; Stucky, G. D. Science 1998, 282, 2244.

(8) Lin, V. S. Y.; Lai, C. Y.; Huang, J. G.; Song, S. A.; Xu, S. J. Am. Chem. Soc. 2001, 123, 11510.

(9) Izquierdo-Barba, I.; Colilla, M.; Vallet-Regí1, M. J. Nanomater. 2008, 2008, 1. were more akin to the conditions for the synthesis of biorelevant composites. ${ }^{14}$ Moreover, various surfactants, including neutral, cationic, anionic, and zwitterionic surfactants, and block copolymers are good templates for the acidic synthesis. The mechanism of growth of such materials has been thought to be driven by the electrostatic interactions, and the "charge density matching" model has been proposed to describe the assembly process between the inorganic species and the micelles. Under acidic conditions with $\mathrm{pH}$ below the isoelectric point of silanol, the protonated silanols $\left(\mathrm{I}^{+}\right)$are proposed to react with positively charged surfactants $\left(\mathrm{S}^{+}\right)$via the counteranions $\left(\mathrm{X}^{-}\right)$through a $\mathrm{S}^{+} \mathrm{X}^{-} \mathrm{I}^{+}$type interaction. Mesoporous materials of more versatile structures and morphologies were obtained in comparison to the alkaline synthesis, due to the weaker $\mathrm{S}^{+} \mathrm{X}^{-} \mathrm{I}^{+}$interaction between the silica and the micelles. ${ }^{12,16,17}$ However, the mechanism associated with this self-assembly process has not been directly proved, and the $\mathrm{S}^{+} \mathrm{X}^{-} \mathrm{I}^{+}$model is often challenged. ${ }^{18}$

(10) Kresge, C. T.; Leonowicz, M. E.; Roth, W. J.; Vartuli, J. C.; Beck, J. S. Nature 1992, 359, 710.

(11) Monnier, A.; Schuth, F.; Huo, Q.; Kumar, D.; Margolese, D.; Maxwell, R. S.; Stucky, G. D.; Krishnamurty, M.; Petroff, P.; Firouzi, A. M.; Chmelka, B. F. Science 1993, 261, 1299.

(12) Huo, Q. S.; Margolese, D. I.; Ciesla, U.; Feng, P.; Gler, T. E.; Sieger, P.; Leon, R.; Petroff, P. M.; Schuth, F.; Stucky, G. D. Nature 1994, $368,317$.

(13) Huo, Q. S.; Margolese, D. I.; Stucky, G. D. Chem. Mater. 1996, 8, 1147.

(14) Mann, S. Nature 1988, 332, 119.

(15) Che, S.; Lim, S.; Kaneda, M.; Yoshitake, H.; Terasaki, O.; Tatsumi, T. J. Am. Chem. Soc. 2002, 124, 13962.

(16) Huo, Q. S.; Margolese, D. I.; Ciesla, U.; Demuth, D. G.; Feng, P.; Gler, T. E.; Sieger, P.; Firouzi, A.; Chmelka, B. F.; Schueth, F.; Stucky, G. D. Chem. Mater. 1994, 6, 1176.

(17) Lin, H. P.; Liu, S. B.; Mou, C. Y. Chem. Commun. 1999, 583. 
Most of the previous studies of the anionic effect on mesoporous silica used cetyltrimethylammonium (CTMA) as the cationic template, and no changes in mesostructures were observed upon varying the anions. ${ }^{17}$ Nevertheless, changes in the hydrolysis rates of the silica precursors, the morphologies, surface properties, and hydrothermal stability of the silica products were reported. ${ }^{19-22}$ In contrast, when cetyltriethylammonium (CTEA) of a relatively large headgroup was used as the surfactant, four types of mesophases including 3Dhexagonal $P 6_{3} / m m c$, cubic Pm3n, 2D-hexagonal $p 6 m m$, and cubic $I a 3 d$ were obtained in different acids. ${ }^{15}$ However, the framework of mesostructured silica templated by CTEA micelles is relatively delicate in comparison to that made by CTMA, due to less degree of silica condensation as proved by ${ }^{29} \mathrm{Si} \mathrm{MAS}$ NMR. ${ }^{23}$ Some of the mesophases undergo phase transformation upon drying the as-made silica materials. ${ }^{23-25}$ As a result, faulty formation mechanisms and incorrect intermediate phases have been proposed due to underestimating the fragility of the mesostructured silica. ${ }^{15,26,27}$

The relationship between the shape of the surfactant monomer and the morphology of an aggregate micelle has been described by the packing parameter approach. ${ }^{28}$ The packing parameter $(g)$ is calculated by the equation $g=V /\left(a_{0} l\right)$, where $V$ is the volume of the hydrocarbon part of the surfactant, $l$ is the length of the extended all-trans alkyl tail, and $a_{\mathrm{o}}$ is the effective surface area of the headgroup. Geometrically, the micelles are spherical for $g \leq 1 / 3$ and ellipsoidal and cylindrical for $1 / 3<g<1 / 2$. The surfactant aggregates become bilayers for $g>1 / 2$ and, under suitable conditions in aqueous solutions, may result in the formation of vesicles. The effective headgroup area $a_{0}$ can be altered by either adding salts to the micellar solution or changing the solution temperature, and that results in changes in micellar shape. The counterions of ionic surfactants can also have a great influence on the morphology of the surfactant aggregates. ${ }^{29}$ With a counterion of stronger bonding strength toward the headgroup of the surfactant, the effective area of the headgroup is considered to decrease and the micellar morphology of less curvature would form. ${ }^{30,31}$

In the present study, the $\mathrm{S}^{+} \mathrm{X}^{-} \mathrm{I}^{+}$type assembly process is verified for the first time by examining the ion-exchange capabilities of the interfacial anions between the micelles and silica wall. Not only a remarkable structural transformation of the silica materials was observed accompanying with the anion

(18) Egger, C. C.; Anderson, M. W.; Tiddy, G. J. T.; Casci, J. L. Phys. Chem. Chem. Phys. 2005, 7, 1845.

(19) Cheng, Y. R.; Lin, H. P.; Mou, C. Y. Phys. Chem. Chem. Phys. 1999, 1,5051 .

(20) Badiei, A. R.; Cantournet, S.; Morin, M.; Bonneviot, L. Langmuir 1998, 14, 7087.

(21) Ryoo, R.; Jun, S. J. Phys. Chem. B 1997, 101, 317.

(22) Lin, H. P.; Mou, C. Y. Microporous Mesoporous Mater. 2002, 55, 69.

(23) Liu, M. C.; Sheu, H. S.; Cheng, S. F. Chem. Commun. 2002, 2854

(24) Liu, M. C. Ph.D. Dissertation, National Taiwan University, Taipei, Taiwan, ROC, 2005.

(25) Ogura, M.; Miyishi, H.; Naik, S. P.; Okubo, T. J. Am. Chem. Soc. 2004, 126, 10937.

(26) Kim, M. J.; Ryoo, R. Chem. Mater. 1999, 11, 487.

(27) Che, S.; Li, H.; Lim, S.; Sakamoto, Y.; Terasaka, O.; Tatsumi, T. Chem. Mater. 2005, 17, 4103.

(28) Israelachvili, J. N.; Mitchel, D. J.; Ninham, B. W. J. Chem. Soc., Faraday Trans. 2 1976, 72, 1525.

(29) Bijma, K.; Rank, E.; Engberts, J. B. F. N. J. Colloid Interface Sci. 1998, 205, 245.

(30) Ray, A.; Nemethy, G. J. Am. Chem. Soc. 1971, 93, 6787.

(31) Gaillon, L.; Lelievere, J.; Gaboriaud, R. J. Colloid Interface Sci. 1999, $213,287$. exchange but also the influences of the anions in micelle morphology and silica architecture were clarified. In situ smallangle X-ray scattering (SAXS) technique was used to study the structural changes of the as-made mesoporous materials during the ion exchange without the interference from the drying process, and a fluorescence quenching experiment of pyrene was employed to semiquantitatively follow the ion-exchange processes.

\section{Experimental Section}

Mesoporous silica was prepared following the procedures described previously. ${ }^{15}$ The molar composition of the synthesis gel was TEOS/CTEABr/acid/ $\mathrm{H}_{2} \mathrm{O}=1: 0.13: 3.0: 125$. The acids used in the present study were $\mathrm{H}_{2} \mathrm{SO}_{4}, \mathrm{HCl}$, and $\mathrm{HNO}_{3}$. Typically, the aqueous solution containing $\mathrm{CTEABr}$ surfactant and acid was stirred at room temperature for $1 \mathrm{~h}$, then at $0{ }^{\circ} \mathrm{C}$ for another hour. To this solution was added precooled TEOS, and the mixture was stirred for $10 \mathrm{~min}$ before it was aged at $0{ }^{\circ} \mathrm{C}$ for $3 \mathrm{~h}$. The resultant precipitate was filtered and transferred immediately to an aqueous solution of various salts. Salts including $\mathrm{NaHSO}_{4}, \mathrm{NaH}_{2} \mathrm{PO}_{4}, \mathrm{NaCl}$, $\mathrm{NaBr}, \mathrm{NaNO}_{3}$, and $\mathrm{NaSCN}$ were used to study the effect of anions. To avoid leaching of the surfactant from the mesostructured silica, CTEABr was also added to the salt solutions except for $\mathrm{NaSCN}$, in which the precipitate formed promptly upon adding CTEABr. The concentrations of the salts and CTEABr were 1.33 and 0.058 $\mathrm{M}$, respectively, the same as those in the initial synthesis solutions. To avoid interference from the drying process, in situ small-angle $\mathrm{X}$-ray scattering (SAXS) technique was used to examine the structural changes of the wet mesoporous materials during the anionexchange processes. The experiments were conducted at National Synchrotron Radiation Research Center (NSRRC), Hsinchu, Taiwan. The reaction mixture was sealed in a Teflon container of 10 $\mathrm{mm}$ inner diameter and ca. $2 \mathrm{~mm}$ thickness with Kapton windows. The SAXS patterns were recorded in the transmission mode with $\lambda=1.32-1.33 \mathrm{~nm}$ radiation $(1.5 \mathrm{GeV}$ and $120-200 \mathrm{~mA})$. The SAXS data were expressed in scattering vector $q$, where $q=4 \pi$ $\sin \theta / \lambda=2 \pi / d$, and $d$ is the $d$ spacing between scattering planes.

For the purpose of probing the interfacial anions between the micelle and silica wall during the ion-exchange process, a trace amount of pyrene was dissolved in the CTEA micelles and the in situ fluorescence spectra of pyrene were taken to determine the exchangeability and distribution of the interfacial anions. Then, 0.29 $\mathrm{mL}$ of $1.03 \mathrm{mM}$ pyrene in ethanol was introduced into a volumetric flask and spread over the flask wall. After evaporating the ethanol in a gentle stream of nitrogen, an aqueous solution of CTEABr $(100 \mathrm{~mL}, 0.058 \mathrm{M})$ was introduced into the flask and the mixture was stirred at $30{ }^{\circ} \mathrm{C}$ for at least $12 \mathrm{~h}$. The pyrene concentration was ca. $3 \mu \mathrm{M}$. To form mesoporous silica materials, the acid $(\mathrm{HCl}$, $\mathrm{H}_{2} \mathrm{SO}_{4}$, or $\mathrm{HNO}_{3}$ ) was introduced and the solution was stirred at 0 ${ }^{\circ} \mathrm{C}$ for $1 \mathrm{~h}$. To this solution was added precooled TEOS, and the mixture was stirred for $5 \mathrm{~min}$ before aged at $0{ }^{\circ} \mathrm{C}$ for $3 \mathrm{~h}$. Typically, the molar composition of the reaction mixture was CTEABr/Py/ TEOS/acid $/ \mathrm{H}_{2} \mathrm{O}=0.13:\left(6.7 \times 10^{-6}\right): 1: 3: 125$. The precipitate was then separated by filtration, and the fluorescence spectra of the precipitates were taken immediately. Steady-state fluorescence measurements were performed using an EDINBURGH FS900 fluorescence spectrometer. Pyrene was excited with a $338 \mathrm{~nm}$ light source, and the emission was collected in the wavelength range of $350-600 \mathrm{~nm}$. The fluorescence lifetime $(\tau)$ of pyrene was measured by a time-correlated single-photon counting apparatus at ambient temperature. Samples were excited with $338 \mathrm{~nm}$ light source, and the detection was at $395 \mathrm{~nm}$.

Optical microscopic images of the materials in the synthesis solutions without any treatment were taken with a Zeiss optical microscope. SEM images of the dried powder samples supported on $\mathrm{Cu}$ net holders and coated with a thin layer of gold by vacuum 


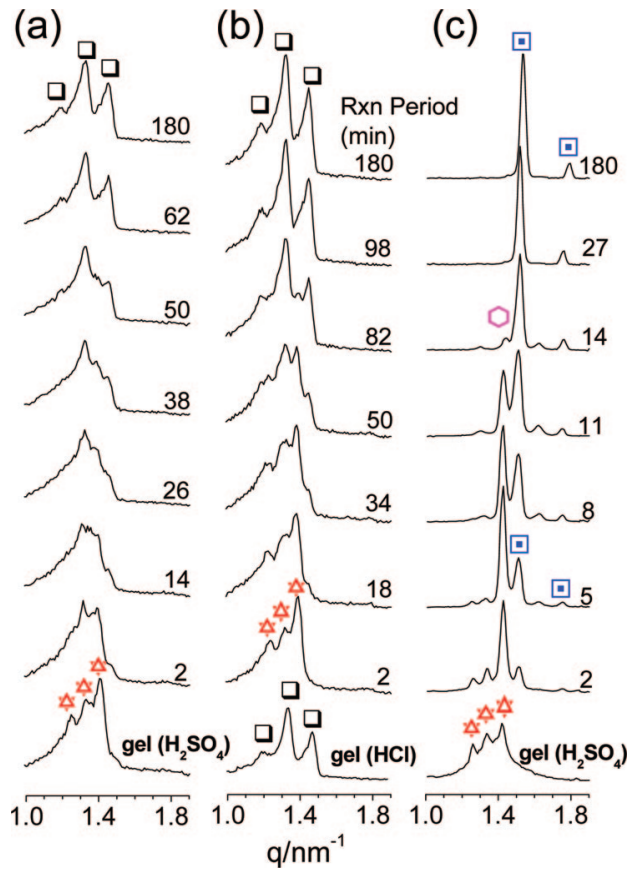

Figure 1. In situ SAXS patterns of mesostructured silica precipitated in (a) $\mathrm{H}_{2} \mathrm{SO}_{4}$ then ion-exchanged with $\mathrm{NaCl}$ solution, (b) $\mathrm{HCl}$ then ionexchanged with $\mathrm{NaHSO}_{4}$ solution, and (c) $\mathrm{H}_{2} \mathrm{SO}_{4}$ then ion-exchanged with NaSCN (red: $3-\mathrm{D} \mathrm{P}_{3} / m m c$; black: cubic $P m 3 n$; pink: 2-D p6mm; blue: cubic $I a 3 d$ )

sputtering were taken using a Hitachi S-800 field emission scanning electron microscope.

\section{Results and Discussion}

Phase Transformation Studied by In Situ Small-Angle X-ray Scattering. For the purpose of following the phase transformation in time course and avoiding the interference upon drying, in situ small-angle X-ray scattering (SAXS) technique was used to examine the structural changes of the wet materials during the ion-exchange processes. Figure 1a shows that the 3D-hexagonal $\mathrm{P6}_{3} / \mathrm{mmc}$ phase was the mesostructured silica precipitated in $\mathrm{H}_{2} \mathrm{SO}_{4}$, characterized by the (100), (101), and (002) scattering peaks at $1.25,1.33$, and $1.41 \mathrm{~nm}^{-1}$, respectively. ${ }^{15,24}$ When the precipitate was immersed in the $\mathrm{NaCl}$ solution, the mesophase transformed gradually in $62 \mathrm{~min}$ to cubic Pm3n, characterized by the (200), (210), and (211) scattering peaks at $1.19,1.32$, and $1.45 \mathrm{~nm}^{-1}$, respectively. The phase transformation was from the mesopores of higher curvature to a lower one. The final cubic $P m 3 n$ phase is also the mesostructure obtained in $\mathrm{HCl}$ solution. On the other hand, when immersing the precipitate formed in $\mathrm{HCl}$ into a $\mathrm{NaHSO}_{4}$ solution, the three peaks of cubic $P m 3 n$ disappeared and another three peaks corresponding to 3D-hexagonal appeared in 2 min (Figure 1b). As time progressed, however, the peaks of the 3D-hexagonal broadened and weakened, while those of cubic Pm $3 n$ grew again and predominated the scattering patterns after $98 \mathrm{~min}$. These results demonstrate that the interfacial anions between the CTEA micelle and silica are exchangeable and the $\mathrm{Cl}^{-}$ion is more dominant than $\mathrm{HSO}_{4}{ }^{-}$in influencing the final mesophase.

Figure 1c is an example of consecutive phase transformation on the silica material precipitated in $\mathrm{H}_{2} \mathrm{SO}_{4}$ and ion-exchanged with a NaSCN solution. After immersing the solid in the NaSCN solution for $2 \mathrm{~min}$, the three peaks of the 3D-hexagonal $\mathrm{PG}_{3} /$ $m m c$ phase of the as-made precipitate weakened and new scattering peaks corresponding to 2D-hexagonal and cubic Ia3d phases appeared. As time progressed to $8 \mathrm{~min}$, the peaks of original 3D-hexagonal phase vanished. The peaks of the 2-D hexagonal reached a maximum at $5 \mathrm{~min}$ and then declined gradually until completely disappearing after $27 \mathrm{~min}$. On the other hand, the peaks of the cubic $I a 3 d$ phase grew stronger and were retained until the end. Therefore, the 2D-hexagonal phase was only an intermediate phase before equilibrium. The changes in micelle structures and phase transformation accompanying the anion exchange of interfacial $\mathrm{HSO}_{4}{ }^{-}$with $\mathrm{SCN}^{-}$ are schematically represented in Figure 2.

Figure 3 graphically summarizes the silica mesophases obtained in different acids and those after ion exchange with various anions of sodium salts. The phase transformation usually reaches equilibrium in $3 \mathrm{~h}$, and the final silica mesophase is a function of the counteranions of the sodium salts. The mesophase was cubic Pm3n in $\mathrm{NaHSO}_{4}, \mathrm{NaH}_{2} \mathrm{PO}_{4}$, and $\mathrm{NaCl}, 2 \mathrm{D}-$ hexagonal in $\mathrm{NaBr}$ and $\mathrm{NaNO}_{3}$, and cubic Ia3d phase in NaSCN. It is also noticeable that the phase transformations induced by interfacial anion exchange are all from porous structure of higher curvature to that of lower one. On the other hand, the silica mesostructures prepared in different acids show different tolerances toward phase transformation upon anion exchange. For the 2D-hexagonal mesostructure synthesized in $\mathrm{HNO}_{3}$, no phase transformation was observed, except in NaSCN. In contrast, the 3-D hexagonal $P 6_{3} / m m c$ mesostructure synthesized in $\mathrm{H}_{2} \mathrm{SO}_{4}$ always has phase transformation upon anion exchange. The final mesophase of the silica is determined by the anion species in the interface, and the influence of anions on phase transformation increases in the order of $\mathrm{HSO}_{4}{ }^{-}<\mathrm{H}_{2} \mathrm{PO}_{4}{ }^{-} \sim$ $\mathrm{Cl}^{-}<\mathrm{Br}^{-} \sim \mathrm{NO}_{3}{ }^{-}<\mathrm{SCN}^{-}$, which follows the Hofmeister series of salting-in. ${ }^{31,32}$ Worthy of notice, these results also indicate that mesoporous silica of cubic Ia3d phase, which is difficult to obtain by conventional methods in mineral acids, can be facilely prepared by ion exchange of the mesotructured silica obtained in either $\mathrm{H}_{2} \mathrm{SO}_{4}, \mathrm{HCl}$, or $\mathrm{HNO}_{3}$ with a $\mathrm{NaSCN}$ solution.

The Hofmeister series arrange the ions with increasing saltingin potency in the order of $\mathrm{SO}_{4}{ }^{2-}<\mathrm{HPO}_{4}{ }^{2-}<\mathrm{F}^{-}<\mathrm{OAc}^{-}<\mathrm{Cl}^{-}$ $<\mathrm{Br}^{-}<\mathrm{NO}_{3}{ }^{-}<\mathrm{SCN}^{-} .33,34$ The ions on the left of the series, generally called salting-out ions, water structure makers, or kosmotropic ions, reduce the solubility of proteins by inducing their crystallization. The ions on the right, known as salting-in, water structure breakers, or chaotropic ions, usually lead to increased solubility of proteins and induce protein denaturation. The chaotropic ions are usually larger, with significant polarizability, and exhibit weaker interactions with water. ${ }^{35-37}$

Morphology Changes of Silica with Interfacial Anion Exchange. The morphologies of the mesostructured silica materials synthesized in $\mathrm{H}_{2} \mathrm{SO}_{4}, \mathrm{HCl}$, and $\mathrm{HNO}_{3}$ were examined by both scanning electron and optical microscopies. These two microscopic techniques have different ways of sample preparation, and the resolution of SEM is much higher than that of an optical microscope. However, the sample for SEM study has to be dried (due to high vacuum requirement of the electron beam) and is usually ground into fine powders. In contrast, the sample can be either wet gel or dried powder using an optical microscope. Therefore, the morphology of the material in the

(32) Hofmeister, F. Arch. Exp. Pathol. Pharmacol. 1888, 24, 247.

(33) Cacace, M. G.; Landau, E. M.; Ramsden, J. J. Q. Rev. Biophys. 1997, $30,241$.

(34) Leontidis, E. Curr. Opin. Colloid Interface Sci. 2002, 7, 81.

(35) Koop, T.; Luo, B.; Tsias, A.; Peter, T. Nature 2000, 406, 611.

(36) Baldwin, R. L. Biophys. J. 1996, 71, 2056.

(37) Collins, K. D.; Washabaugh, M. W. Q. Rev. Biophys. 1985, 18, 323. 


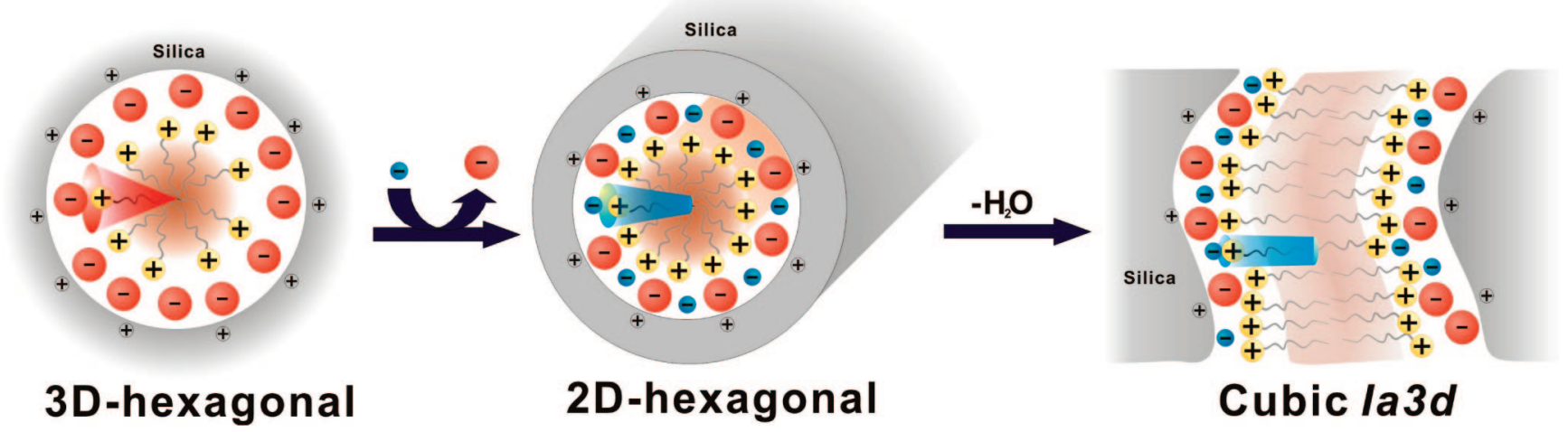

Figure 2. Schematic representation of the mesophase transformation of silica precipitated in $\mathrm{H}_{2} \mathrm{SO}_{4}$ then ion-exchanged with $\mathrm{NaSCN}$.

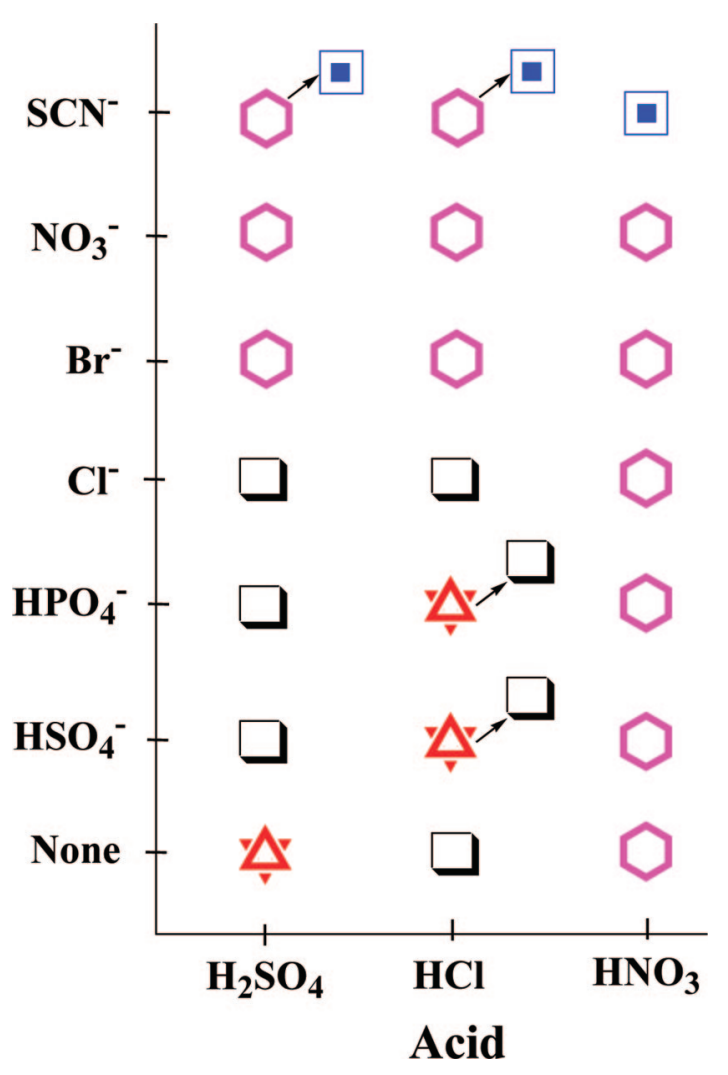

Figure 3. Phase diagram of the mesoporous silica materials formed in different acids and ion-exchanged with various sodium salt solutions based on in situ SAXS data (red: $3-\mathrm{D} P 6_{3} / m m c$; black: cubic $P m 3 n$; pink: 2-D p6mm; blue: cubic $I a 3 d$ ).

synthesis solution can be in situ examined with an optical microscope, which avoids the interferences from drying and grinding the solid samples.

The SEM photographs of the solid samples that precipitated for $3 \mathrm{~h}$ in the synthesis solutions of different acids all show irregular shapes. However, those crystallized for $24 \mathrm{~h}$ are spherical from $\mathrm{H}_{2} \mathrm{SO}_{4}$ and $\mathrm{HCl}$, and gyroid particles are from $\mathrm{HNO}_{3}$. Similar morphologies were also observed by Che et al. ${ }^{27}$ They designated the irregular monoliths obtained in $\mathrm{HNO}_{3}$ for short periods of crystallization to lamellar and cubic Ia3d mesophases and the gyroid obtained for longer period of crystallization to 2-D hexagonal mesophase. Accordingly, they proposed that the lamellar and cubic Ia $3 d$ phases were formed in the early stage of reaction, and the 2-D hexagonal phase was a result of phase transformation as the reaction progressed. However, in situ XRD experiments carried out by Ogura et al. ${ }^{25}$ and our laboratory ${ }^{24}$ have clarified that no phase transformation occurs in the synthesis solution of $\mathrm{HNO}_{3}$. The lamellar and cubic Ia $3 d$ phases are actually a result of phase transformation from drying the 2-D hexagonal mesostructured silica formed in $\mathrm{HNO}_{3}$ with a low degree of silicate condensation. These results imply that the morphologies of the mesostructured silica may be varied during the drying process or sample preparation.

To correlate the morphologies of silica materials with the mesophases without interferences from drying and specimen preparation, an optical microscope was used to detect the wet samples. Figure $4 \mathrm{a}-\mathrm{f}$ shows that only spherical particles are seen in the gels crystallized in $\mathrm{H}_{2} \mathrm{SO}_{4}$ and $\mathrm{HCl}$, while those precipitated in $\mathrm{HNO}_{3}$ have the rod and top shapes. Moreover, no changes in morphologies were observed on the gels precipitated in any of the acids when the crystallization was prolonged from $3 \mathrm{~h}$ to 1 day. It was also noticed that the morphologies were retained when the wet gels were left on the slides and dried in air. However, the solids crystallized in acids for only $3 \mathrm{~h}$ were fragile, and the particles were broken down to pieces when applying the gels on the slide with a spoon. Therefore, the irregular shape of the particles observed by SEM on the dried samples crystallized for a short period of time is likely a result of particle breakdown during filtration and grinding.

As phase transformation was induced by anion exchange, the morphologies of the mesostructured silica materials were found to vary also. Figure $4 \mathrm{~g}$ shows that the precipitate recovered from $\mathrm{H}_{2} \mathrm{SO}_{4}$ for $3 \mathrm{~h}$ after ion exchange with $\mathrm{NaNO}_{3}$ for $1 \mathrm{~h}$ has the mushroom-like morphology with a particle size similar to that before immersing in $\mathrm{NaNO}_{3}$. At this moment, phase transformation should have occurred and the mesostructured material is no longer 3D-hexagonal. After ion exchange in $\mathrm{NaNO}_{3}$ for 1 day, the particles became the top shape, similar to that precipitated in $\mathrm{HNO}_{3}$ (Figure 4, panel h vs panels e and f).

SEM photograph shows that the as-made silica precipitated in $\mathrm{H}_{2} \mathrm{SO}_{4}$ for 1 day produces $6-10 \mu \mathrm{m}$ spheres (Figure 5a), which are similar to that observed by an optical microscope (Figure 4b). After immersing the solid precipitated in $\mathrm{H}_{2} \mathrm{SO}_{4}$ for $3 \mathrm{~h}$ to the $\mathrm{NaCl}$ solution for 1 day, although the material is transformed to the cubic $P m 3 n$ phase, most of the particles are still spheres with multifaces (Figure $5 \mathrm{~b}$ ). On the other hand, the same precipitate immersed in $\mathrm{NaNO}_{3}$ has the particles in whirligig or short rod shapes (Figure 5c), corresponding to phase transformation to 2D-hexagonal. As to that immersed in NaSCN, the final mesostructure is cubic Ia $3 d$ and the solids are spheres with faces again (Figure 5d). These results confirm that the interfacial anions not only affect the pore structures formed 

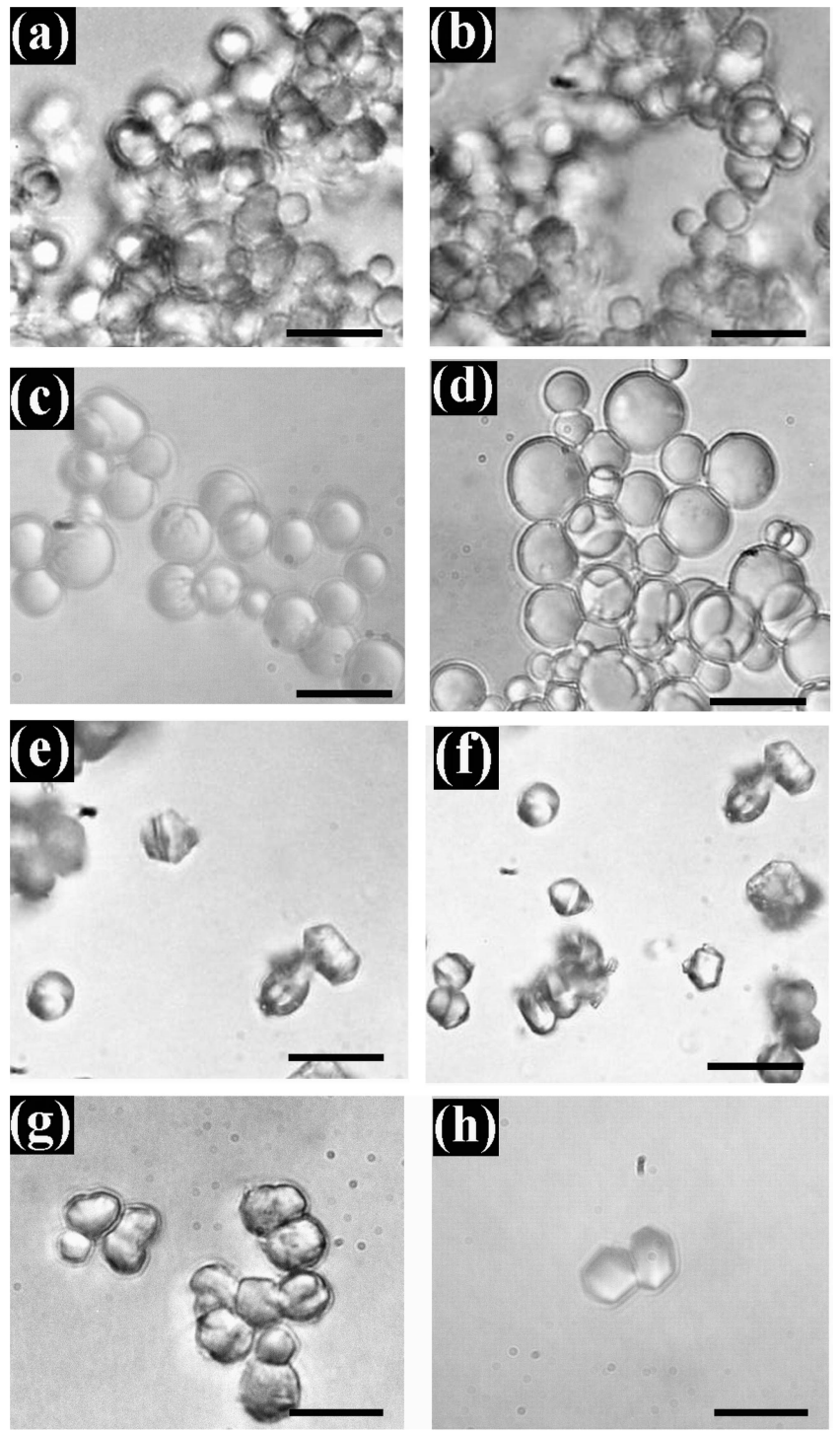

Figure 4. Optical microscopic images of wet mesostructured silica precipitated in $\mathrm{H}_{2} \mathrm{SO}_{4}$ for (a) $3 \mathrm{~h}$ and (b) 1day, in $\mathrm{HCl}$ for (c) $3 \mathrm{~h}$ and (d) 1 day, and in $\mathrm{HNO}_{3}$ for (e) $3 \mathrm{~h}$ and (f) 1 day, and that precipitated in $\mathrm{H}_{2} \mathrm{SO}_{4}$ for $3 \mathrm{~h}$ and ion-exchanged with $\mathrm{NaNO}_{3}$ for $(\mathrm{g}) 1 \mathrm{~h}$ and $(\mathrm{h}) 1$ day. The scale bar is $10 \mu \mathrm{m}$.

around CTEA micelles but also influence the architecture of silica framework and the morphology of the silica material. Since the changes observed on the dried samples with SEM are consistent with those of wet gels observed by optical microscopy, the ion-exchanged samples are stable upon drying.

Interfacial Anion Exchange Probed by Pyrene Fluorescence. For the purpose of in situ detecting the exchangeability and distribution of interfacial anions between the micelle and silica wall, pyrene was dissolved in the CTEA micelles and the fluorescence spectra of pyrene were taken during ion exchange. Fluorescent aromatic hydrocarbons such as pyrene (Py) have been widely used to probe the microenvironment of organized host media, such as micelles, microdroplets, vesicles, etc. $^{38-40}$ The pyrene fluorescence fine structure shows five

(38) Kalyanasundraram, K. Photochemistry in Microheterogeneous Systems; Academic Press: New York, 1987.

(39) Kalyanasundaram, K.; Thomas, J. K. J. Am. Chem. Soc. 1977, 99, 2039.

(40) Dong, D. C.; Winnik, M. A. Can. J. Chem. 1984, 162, 2560.

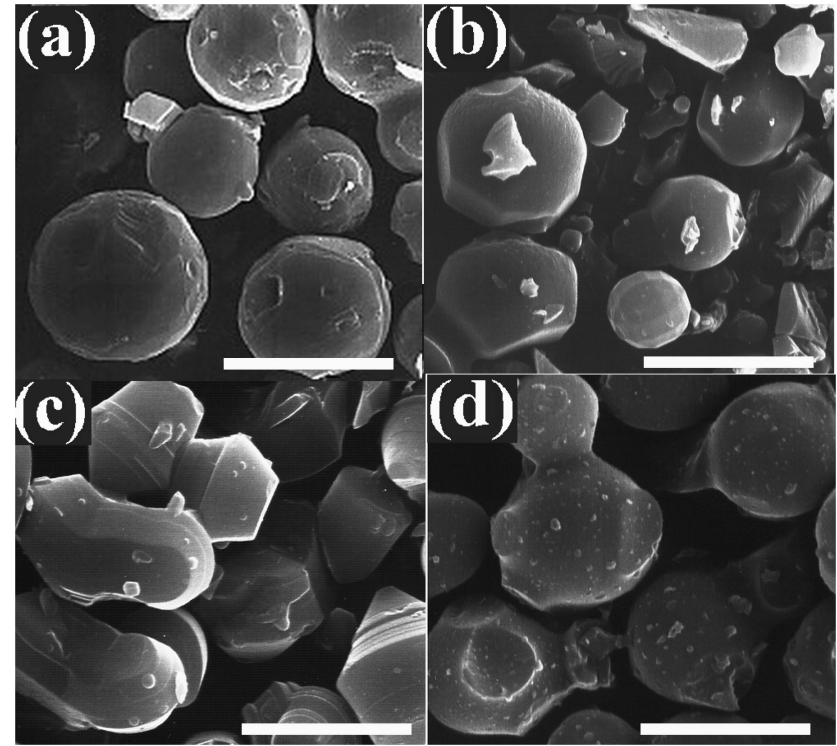

Figure 5. SEM micrographs of (a) as-made mesoporous silica precipitated in $\mathrm{H}_{2} \mathrm{SO}_{4}$, and those after ion exchange with (b) $\mathrm{NaCl}$, (c) $\mathrm{NaNO}_{3}$, and (d) NaSCN for 1 day. The scale bar is $10 \mu \mathrm{m}$.

predominant peaks in the $\mathrm{UV}-$ vis region (Figure 6A). ${ }^{40}$ The 0-0 transition from the ground state to the lowest excited electronic state gives rise to the $I_{1}$ peak at $374 \mathrm{~nm}$, which is symmetry-forbidden. Its intensity is increased by the distortion of the $\pi$-electron cloud in polar media, while the $I_{3}$ peak at 385 $\mathrm{nm}$ is not forbidden and solvent-insensitive. As a result, the $I_{1} / I_{3}$ ratio is smaller when the microenvironment of pyrene is less polar. ${ }^{39}$ In water, the $I_{1} / I_{3}$ ratio is 1.7 , whereas it has a value well below 1 in apolar solvents (e.g., 0.58 in cyclohexane). ${ }^{40}$ Therefore, the $I_{1} / I_{3}$ ratio is used as an indicator of the polarity around pyrene.

The $I_{1} / I_{3}$ intensity ratios were determined to be $1.59,1.54$, and 1.51 for the mesostructured silica precipitated in $\mathrm{H}_{2} \mathrm{SO}_{4}$, $\mathrm{HCl}$, and $\mathrm{HNO}_{3}$, respectively. These values are close to 1.54 for pyrene-containing CTEA micelles in the aqueous solutions of above three acids, implying that the local environment of pyrene in the micelles, which embedded in mesostructured silica as the template, is similar to that in aqueous solutions. That also infers that the headgroups of CTEA surfactants are surrounded by water or a significant amount of water should be present in the interface between the micelle and silica wall. Although pyrene should dissolve in the hydrophobic part of the micelle, the $I_{1} / I_{3}$ intensity ratios show that it is likely sitting a short distance from the headgroups of the micelle instead of at the center of the hydrophobic core. Nevertheless, the $I_{1} / I_{3}$ intensity ratios show that the microenvironment around micelle headgroups is slightly affected by the acids and the polarity decreases in the order of $\mathrm{H}_{2} \mathrm{SO}_{4}>\mathrm{HCl}>\mathrm{HNO}_{3}$. This trend is consistent with the proposal that the chaotropic ions with more positive entropies of hydration act like hydrophobic molecules. ${ }^{41}$

The fluorescence lifetime $(\tau)$ of pyrene was measured by timecorrelated single-photon counting apparatus at ambient temperature. Samples were excited with $338 \mathrm{~nm}$ light source, and the detection was made at $395 \mathrm{~nm}$ (Figure 6B). The fluorescence decay profiles were analyzed with a nonlinear least-squares iterative reconvolution method. Table 1 shows the mesophases and the $\tau$ values of mesostructured silica precipitated in different

(41) Karlstroem, G. Phys. Chem. Chem. Phys. 2003, 5, 3238. 
(A)

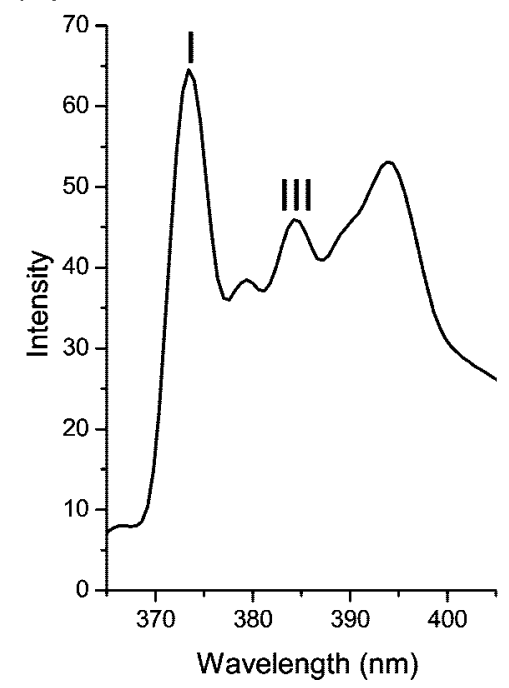

(B)

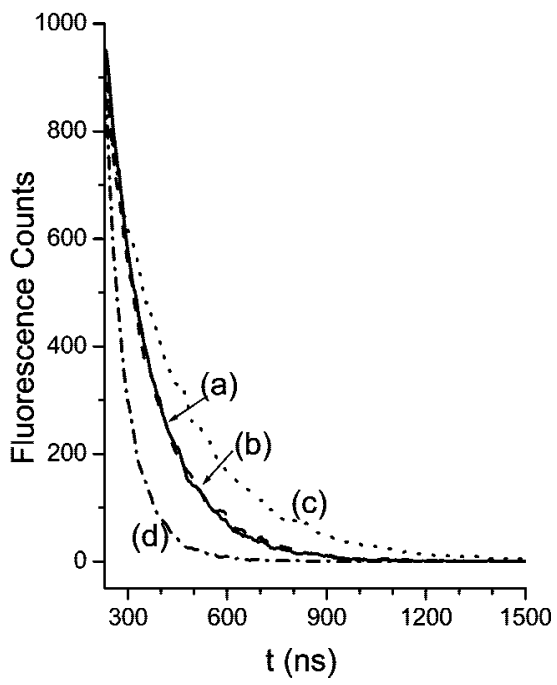

Figure 6. (A) Typical emission spectrum of pyrene, and (B) fluorescence lifetime of pyrene in mesoporous materials prepared in (a) $\mathrm{H}_{2} \mathrm{SO}_{4}$, and those after ion exchange with (b) $\mathrm{NaHSO}_{4}$, (c) $\mathrm{NaCl}$, and (d) $\mathrm{NaNO}_{3}$ for $3 \mathrm{~h}$.

Table 1. Lifetimes $(\tau)$ of Pyrene and Mesophases of the Silica Precipitated in Different Acids and after Ion-Exchanged with Various Salt Solutions for $3 \mathrm{~h}$

\begin{tabular}{|c|c|c|c|c|c|c|}
\hline \multirow[b]{2}{*}{ salts } & \multicolumn{2}{|r|}{$\mathrm{H}_{2} \mathrm{SO}_{4}$} & \multicolumn{2}{|r|}{$\mathrm{HCl}$} & \multicolumn{2}{|r|}{$\mathrm{HNO}_{3}$} \\
\hline & $\tau / \mathrm{ns}$ & mesophase & $\tau / \mathrm{ns}$ & mesophase & $\tau / \mathrm{ns}$ & mesophase \\
\hline- & 199 & 3-D $\mathrm{P}_{3} / m m c$ & 203 & cubic $P m 3 n$ & 72 & 2-D p6mm \\
\hline $\mathrm{NaHSO}_{4}$ & 199 & cubic $P m 3 n$ & 197 & cubic $P m 3 n$ & 146 & 2-D p6mm \\
\hline $\mathrm{NaCl}$ & 211 & cubic $P m 3 n$ & 213 & cubic $P m 3 n$ & 156 & 2-D p6mm \\
\hline $\mathrm{NaNO}_{3}$ & 147 & 2-D p6mm & 152 & 2-D p6mm & 71 & 2-D p6mm \\
\hline
\end{tabular}

acids in comparison to those after ion exchange in various salt solutions for $3 \mathrm{~h}$. The lifetimes were 199, 203, and $72 \mathrm{~ns}$ for the silica precipitated in $\mathrm{H}_{2} \mathrm{SO}_{4}, \mathrm{HCl}$, and $\mathrm{HNO}_{3}$, respectively, and the corresponding mesophases were 3-D hexagonal $P 6_{3} /$ $m m c$, cubic $P m 3 n$, and 2-D hexagonal $p 6 \mathrm{~mm}$. These results show that the $\mathrm{NO}_{3}{ }^{-}$ion is the most efficient in quenching pyrene fluorescence among the three counteranions, while $\mathrm{HSO}_{4}{ }^{-}$and $\mathrm{Cl}^{-}$ions have similar quenching abilities. For the silica synthesized in $\mathrm{H}_{2} \mathrm{SO}_{4}$ and ion exchange with $\mathrm{NaCl}$, the mesophase transformed from 3-D hexagonal to cubic Pm3n, but the lifetime only changed slightly from 199 to 211 ns. Similar lifetimes were also observed for the silica precipitated in $\mathrm{HCl}$ and ion exchange with $\mathrm{NaHSO}_{4}$ (203 to $197 \mathrm{~ns}$ ). Moreover, the mesophases of the final products in these two experiments were the same cubic $\mathrm{Pm} 3 n$.

For the silica precipitated in $\mathrm{H}_{2} \mathrm{SO}_{4}$ and ion-exchanged with $\mathrm{NaNO}_{3}, \tau$ decreased markedly from 199 to ca. $147 \mathrm{~ns}$, which is a value between those observed in $\mathrm{H}_{2} \mathrm{SO}_{4}$ and $\mathrm{HNO}_{3}$. On the other hand, for the silica precipitated in $\mathrm{HNO}_{3}$ and post-treated in $\mathrm{NaHSO}_{4}, \tau$ increased from 72 to 146 ns. Noticeably, the lifetimes of the final products in these two experiments were close. Similar phenomenon was also observed for the silica precipitated in $\mathrm{HCl}$ then ion-exchanged with $\mathrm{NaNO}_{3}(\tau=152$ ns) and that precipitated in $\mathrm{HNO}_{3}$ and post-treated in $\mathrm{NaCl}(\tau$ $=156 \mathrm{~ns}$ ). These results infer that there should be an equilibrium distribution of the original interfacial anion and the counteranion of sodium salt in the interface between the micelle and the silica wall. By measuring the $\tau$ value as a function of the exchange period, it was found that the anion exchange reaches equilibrium in about $1 \mathrm{~min}$ (Figure 7), which is much faster than the transformation of the silica mesophases. In this case, the final

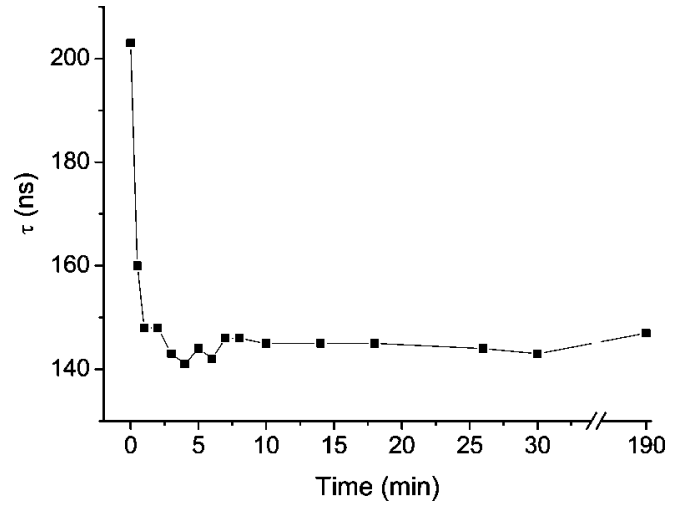

Figure 7. Lifetime change of pyrene in the mesostructured silica precipitated in $\mathrm{HCl}$ after the silica was introduced into a $\mathrm{NaNO}_{3}$ solution.

mesostructures are all 2D-hexagonal. Assuming a linear relationship between the $\tau$ value and the anion concentration, it is estimated by linear equation in one variable that $42-46 \%$ molar ratios of the interfacial anions in the above two systems $\left(\mathrm{Cl}^{-} /\right.$ $\mathrm{NO}_{3}{ }^{-}$and $\mathrm{HSO}_{4}{ }^{-} / \mathrm{NO}_{3}{ }^{-}$) are $\mathrm{NO}_{3}{ }^{-}$ions. These results demonstrate that the chaotropic anions would determine the final mesostructure even though they only occupy about one-half of the interfacial anion sites.

The Nature of Anion Effect. The Hofmeister anion effect on the mesostructured silica has been attributed to the fact that the chaotropic ions bind strongly and closely to the headgroups of the surfactants and partially reduce the electrostatic repulsion between the charged surfactant headgroups, therefore resulting in micelles of low curvature. ${ }^{27,31}$ However, the factors that affect the binding strength of the anions have not been well interpreted. In the present study, the $I_{1} / I_{3}$ intensity ratios of pyrene fluorescence spectra show that the headgroups of CTEA surfactants are surrounded by a significant amount of water in the interface between the micelle and the silica wall. Therefore, the hydrated anions instead of the net anions should be considered in their binding strength to the headgroups of the surfactants. The kosmotropic ions on the left of the Hofmeister series have higher solvation energies due to either the smaller size (such as $\mathrm{Cl}^{-}$) or stronger hydrogen bond (such as $\mathrm{HSO}_{4}^{-}$) 
and form larger hydrated anions, which bind weakly to the headgroups of the surfactants. Contrarily, the chaotropic ions on the right of the series (such as $\mathrm{NO}_{3}^{-}$) have lower solvation energies and form smaller hydrated anions, which bind strongly to the headgroups of the surfactants and have stronger influence on the final phase of the mesostructured silica.

The phase transformation as a function of exchange period observed in Figure 1b,c can be rationalized by the changes in the amount of interfacial water. Figure $1 \mathrm{~b}$ shows a cubic $P m 3 n$ $\rightarrow$ 3D-hexagonal $\rightarrow$ cubic Pm3n transformation during ion exchange of interfacial $\mathrm{Cl}^{-}$with $\mathrm{HSO}_{4}{ }^{-}$ions. Pyrene fluorescence experiment indicates that anion exchange reaches equilibrium in less than 2 min (Figure 7). Accordingly, the 3Dhexagonal phase is formed when $\mathrm{HSO}_{4}{ }^{-}$ions replace about a half-portion of the interfacial chloride. Meanwhile, a large amount of water is probably carried into the interfacial space with the kosmotropic $\mathrm{HSO}_{4}{ }^{-}$ions. The $\mathrm{CTEA}^{+}$micelle of higher curvature is formed due to less neutralization by the counteranions and the stronger electrostatic repulsion between the charged surfactant headgroups. As the reaction proceeds, the interfacial water content is gradually reduced due to the influence of relatively chaotropic $\mathrm{Cl}^{-}$ions remaining at the interface. At last, the micelle of lower curvature responsible for the formation of the cubic $P m 3 n$ mesophase is formed again when the interfacial water content decreases to the static state. The gradual decreases in interfacial water content after anion exchange also account for the appearance of 2D-hexagonal structure as an intermediate phase during the 3D-hexagonal $\rightarrow$ cubic Ia $d$ phase transformation when interfacial $\mathrm{HSO}_{4}{ }^{-}$is exchanged with $\mathrm{SCN}^{-}$ ions, as shown in Figure 1c.

Expansion of Hofmeister Anion Series. The mesophase transformation induced by interfacial anion exchange may provide a unique technique to study anions which are not yet included in the Hofmeister series. Here, the extended series are demonstrated by using three halogen-substituted acetate ions, in comparison to that of nonsubstituted acetate. The mesostructured silica materials precipitated in $\mathrm{H}_{2} \mathrm{SO}_{4}, \mathrm{HCl}$, and $\mathrm{HNO}_{3}$ were introduced to the solutions containing sodium acetates with various halogen substitutions. It was noticeable that the fluorescence lifetime of pyrene dissolved in the micelle of mesostructured silica was changed after ion exchange. For the silica precipitated in $\mathrm{HCl}$, the $\tau$ value decreased from 203 to $129 \mathrm{~ns}$ when it was immersed in the solution of $\mathrm{CF}_{3} \mathrm{COONa}$ and to 82 $\mathrm{ns}$ in that of $\mathrm{CCl}_{3} \mathrm{COONa}$. Moreover, the fluorescence intensity became too weak to detect when the silica was immersed in the solution of $\mathrm{CBr}_{3} \mathrm{COONa}$. These results confirm the exchangeability of interfacial anions between the pore-directing CTEA micelle and the silica wall of mesostructured silica with the acetate ions. It also demonstrates that various halogensubstituted acetate ions have different quenching abilities on the pyrene fluorescence. The positions of these anions in the Hofmeister series are determined by their ability to influence the phase transformation, and the one of more chaotropic character (salting-in) can lead to phase transformation.

First, the gel crystallized in $\mathrm{HNO}_{3}$ was chosen because of the strong binding ability of the $\mathrm{NO}_{3}{ }^{-}$ions to the CTEA micelle. Figure 8 shows the in situ SAXS patterns of the gel crystallized in $\mathrm{HNO}_{3}$ after post-treatment with a solution containing $\mathrm{NaCF}_{3} \mathrm{COO}$ and CTEABr. The 2D-hexagonal phase $(q \sim 1.5$ $\mathrm{nm}^{-1}$ ) gradually disappeared in $45 \mathrm{~min}$, and the cubic Ia3d phase appeared in $3 \mathrm{~min}$. These results imply that $\mathrm{CF}_{3} \mathrm{COO}^{-}$has a stronger influence than $\mathrm{NO}_{3}{ }^{-}$in salting-in ability. Accordingly, the mesophases obtained after ion exchanging mesostructured

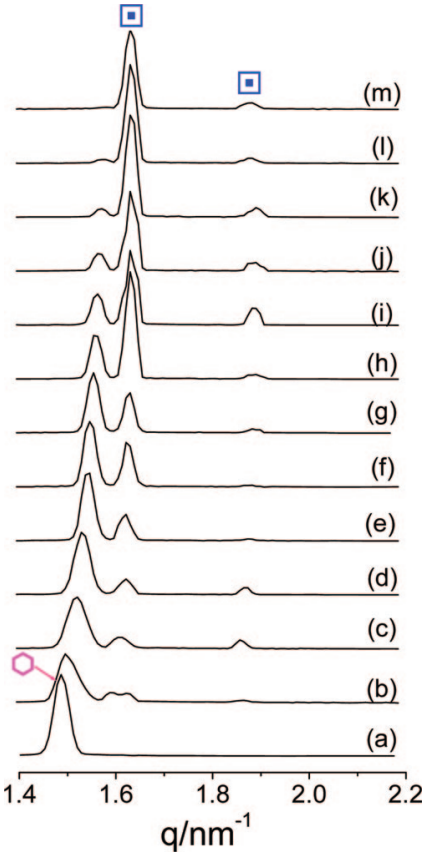

Figure 8. In situ SAXS patterns of mesostructured silica precipitated in (a) $\mathrm{HNO}_{3}$, then ion-exchanged with $\mathrm{CF}_{3} \mathrm{COONa}$ solution for (b) 3, (c) 6 , (d) 9, (e) 12, (f) 15, (g) 18, (h) 21, (i) 24, (j) 27, (k) 30, (l) 36, and (m) 45 min (pink: 2-D p6mm; blue: cubic Ia3d).

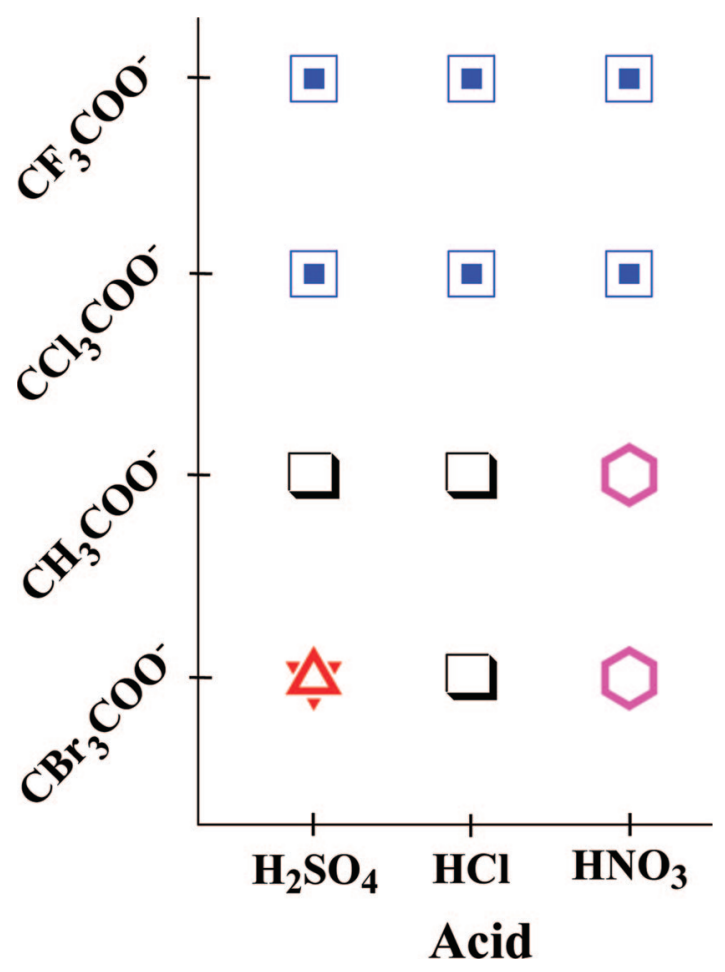

Figure 9. Phase diagram of mesoporous silica precipitated in different acids and ion-exchanged with sodium salts of various halogen-substituted acetates based on in situ SAXS data.

silica with various halogen-substituted acetates are summarized in Figure 9. No phase transformation occurs when immersing the gels precipitated in acids into $\mathrm{CBr}_{3} \mathrm{COONa}$, implying that $\mathrm{CBr}_{3} \mathrm{COO}^{-}$ion is less effective in salting-in than $\mathrm{HSO}_{4}^{-}$, which is the most kosmotropic among the three counteranions of the acids. In $\mathrm{CH}_{3} \mathrm{COONa}$, phase transformation was observed only in the gel precipitated in $\mathrm{H}_{2} \mathrm{SO}_{4}$, implying that the $\mathrm{CH}_{3} \mathrm{COO}^{-}$ 
ion is less powerful in salting-in than $\mathrm{Cl}^{-}$and $\mathrm{NO}_{3}{ }^{-}$but stronger than $\mathrm{HSO}_{4}^{-}$. On the other hand, all the silica materials are transformed to the cubic Ia3d phase after being immersed in $\mathrm{CF}_{3} \mathrm{COONa}$ and $\mathrm{CCl}_{3} \mathrm{COONa}$ solutions. Therefore, the Hofmeister series can be extended to include the halogen-substituted acetate anions in salting-in tendency as $\mathrm{CBr}_{3} \mathrm{COO}^{-}<\mathrm{HSO}_{4}{ }^{-}<$ $\mathrm{CH}_{3} \mathrm{COO}^{-}<\mathrm{Cl}^{-}<\mathrm{NO}_{3}^{-}<\mathrm{CCl}_{3} \mathrm{COO}^{-} \sim \mathrm{CF}_{3} \mathrm{COO}^{-} \sim \mathrm{SCN}^{-}$.

To explain the decrease in chaotropic property from trifluoroacetate to tribromoacetate, again the hydrated anions instead of the net anions should be considered in their binding strength to the headgroups of the surfactants. More electron density is shifted away from the carboxylate site when stronger electronwithdrawing elements are substituted on the adjacent methyl group. The resultant carboxylate site of less charge density attracts a less amount of water as the solvation enthalpy is concerned. As a result, the hydrated trifluoroacetate is probably smaller than hydrated tribromoacetate and binds more strongly and closely to the headgroups of the surfactants. As the chaotropic ions partially reduce the electrostatic repulsion between the charged surfactant headgroups, micelles of lower curvature are formed. The lower electrostatic repulsion between the charged surfactant headgroups also induces the protonated silicate condensated around the micelle to rearrange, and the framework of mesoporous silica is transformed from higher curvature to lower curvature pores.

\section{Conclusions}

The anions present in the interfacial space between the poredirecting CTEA micelle and the silica wall of mesostructured silica are ready to be exchanged, accompanied by phase transformation and morphology change. From the in situ fluorescence quenching experiment of pyrene, which was dissolved in the hydrophobic core of the micelle, the anion exchange proceeds very fast (within minutes) and there is an equilibrium distribution of the original interfacial anion and the counteranion of sodium salt in the interface between the micelle and the silica wall. The crystallographic phase as well as the morphology of mesostructured silica tends to transform from pore structure of low $g$ value to that of high $g$ value, or from a higher pore curvature toward lower one, which follows the Hofmeister series of salting-in. The pyrene luminescence study demonstrates that the hydrated anions instead of the net anions should be considered in their binding strength to the headgroups of the surfactants. The Hofmeister anion effect on the mesostructured silica is attributed to the fact that the chaotropic ions, which have lower solvation energies and form smaller hydrated anions, bind strongly and closely to the headgroups of the surfactants, partially reducing the electrostatic repulsion between the charged surfactant headgroups and inducing the formation of micelles of low curvature. The mesophase transformation induced by the interfacial anion exchange provides a unique technique to study anions which are not yet included in the Hofmeister series. The relative positions of halogen-substituted acetate anions were included in the series to be $\mathrm{CBr}_{3} \mathrm{COO}^{-}<$ $\mathrm{HSO}_{4}{ }^{-}<\mathrm{CH}_{3} \mathrm{COO}^{-}<\mathrm{Cl}^{-}<\mathrm{NO}_{3}{ }^{-}<\mathrm{CCl}_{3} \mathrm{COO}^{-} \sim \mathrm{CF}_{3} \mathrm{COO}^{-}$ $\sim \mathrm{SCN}^{-}$in salting-in power. As a result, the interfacial anionexchange technique may be extended to other anions which are not yet included in the Hofmeister series, and their influences on the biological macromolecules, like proteins, DNA, and lipids, may be predicted. On the other hand, mesoporous silica of cubic $I a 3 d$ phase, which is not readily formed in mineral acids, can be easily prepared by ion exchange with anions of strongest salting-in power.

Acknowledgment. This research was supported by the National Science Council and Ministry of Education, Taiwan. Acknowledgments are also extended to C.-Y. Tang and C.-Y. Lin of Instrumentation Center, National Taiwan University for SEM and TEM experiments. We also thank Profs. P.-T. Chou and J.-S. Yang of Department of Chemistry, and C.-N. Kuo of Department of Chemical Engineering, NTU for the assistance in fluorescence measurement and optical microscopy.

JA808025M 